\title{
El problema del radicalismo cosmológico de Spinoza y Nietzsche: análisis desde dos lecturas nietzscheanas
}

The problem of Spinoza's and Nietzsche's cosmological radicalism: analysis from two Nietzschean readings

\author{
Pablo Martínez BeCERRA (ida
}

\section{Resumen}

Al intentar establecer cuánto debe Nietzsche a Spinoza en la configuración de su visión radical del mundo y quién de los dos da los pasos más decisivos en la disolución de la trascendencia, encontramos diversas dificultades. La primera es que la disputa acerca del ateísmo spinociano parece que no podrá nunca dirimirse en un grado aceptable. La segunda dice relación con la imagen que Nietzsche tiene de Spinoza en tanto puede considerarse sesgada debido al conocimiento indirecto de su obra. La tercera es que para determinar, en parte, qué adeuda la interpretación de Nietzsche al filósofo holandés, se requiere hacer un análisis exhaustivo y pormenorizado de sus autores fuente. Tomando en cuenta estas complejidades, el autor del artículo defiende que para formarse una idea adecuada de la deuda del radicalismo de Nietzsche con Spinoza y para juzgar quién de ellos nos precipita con más relevancia a la pura inmanencia, es necesario ir estudiando sus lecturas sobre el filósofo judío, incluso las más descuidadas, más allá de Kuno Fischer. De acuerdo con ello, en este escrito se analizan dos lecturas de Nietzsche poco utilizadas en esta reflexión, a saber: Heinrich Heine (1797-1856) y Jean-Marie Guyau (1854-1888). Se asume así que, para alcanzar un nivel más alto de claridad en el tema estudiado, se ha de acotar el marco bibliográfico en el que se ha de realizar la hermenéutica de Nietzsche y sus fuentes. Teniendo presente

\footnotetext{
a Universidad de Playa Ancha (UPLA), Valparaíso, Chile. Doctor en Filosofía, Moral y Política, e-mail: pablo.martinez@upla.cl
} 
estos presupuestos, se compara el panteísmo, la desantropomorfización del mundo y el conatus sese conservandi de Spinoza, con el monismo, la extramoralidad del mundo y la voluntad de poder de Nietzsche, respectivamente, para evaluar el alcance del radicalismo cosmológico de uno y otro autor.

Palabras clave: Nietzsche. Spinoza. Heine. Guyau. Radicalismo. Panteísmo. Ateísmo.

\section{Abstract}

In trying to establish how much Nietzsche owes Spinoza in the configuration of his radical view of the world, and which of the two takes the most decisive steps in the dissolution of transcendence, we encounter various difficulties. The first is that the dispute about Spinoza's atheism seems as it will never be settled to an acceptable degree. The second relates to Nietzsche's image of Spinoza, since it might be considered biased due to the indirect knowledge of his work. The third is that to determine, partly, what does Nietzsche's interpretation of the Dutch philosopher owes, requires a thorough and detailed analysis of his source authors. Taking into account these complexities, the author of the article advocates that, in order to form a proper idea of Nietzsche's radicalism debt with Spinoza and to judge which of them precipitates us with more relevance to pure immanence; it is necessary to study his readings on the Jewish philosopher, even the most neglected, beyond Kuno Fischer. Accordingly, this paper analyzes in this reflection two little used readings of Nietzsche; scilicet: Heinrich Heine (1797-1856) y Jean-Marie Guyau (1854-1888). Thus, it is assumed that, in order to reach a higher level of clarity in the studied subject, the bibliographical framework in which Nietzsche's hermeneutics and its sources should be carried out must be narrowed. Keeping these presuppositions in mind, pantheism, the world's deanthropomorphisation and Spinoza's conatus sese conservandi, are compared with monism, the extramorality of the world and Nietzsche's will to power, respectively, in order to evaluate the scope of the cosmological radicalism of one and other author.

Keywords: Nietzsche. Spinoza. Heine. Guyau. Radicalism. Pantheism. Atheism.

\section{Introducción}

Nos habíamos propuesto, en un principio, tratar de determinar en este artículo en qué grado Nietzsche radicalizaba y llevaba al extremo la crítica de Spinoza a la trascendencia y al supuesto orden moral del mundo. Sin embargo, al intentar responder, advertíamos que ya es controversial para los intérpretes poder dar cuenta del horizonte en el que ha pensado el filósofo judío, es decir, cuál es la frontera real de su pensamiento y la intención última de su propuesta. En otras 
palabras, entendíamos que difícilmente podríamos llegar al objetivo de determinar cuál de los dos filósofos asesta el golpe más certero al antiguo orden ontoteológico, si poníamos frente a Nietzsche a un pensamiento spinociano diluido en una hermenéutica controversial.

Conforme a lo dicho, se hacía evidente que para contestar si Nietzsche extrema el pensamiento de Spinoza o sólo empuja lo que él ya había hecho caer, era necesario indagar, antes que todo, en el posible "ateísmo" del autor de la Ética. En otras palabras, era claro que la forma en que contestásemos la pregunta acerca de su ateísmo nos permitiría precisar, bajo un respecto fundamental, los grados en que uno y otro se oponen a los supuestos metafísicos del pensar occidental. No obstante, algo sí estaba claro, al punto que no lo podíamos soslayar: consideremos a Spinoza, “ateo", “acósmico", “cosmoteísta”, o le demos cualquier nombre a su doctrina que permita desmarcarlo del ateísmo, lo cierto es que su teología parece constituir un capítulo fundamental hacia la "muerte de Dios".

Mas, decir que Spinoza representa un instante estelar de la lucha contra el Dios trascendente, no significa haber definido su real posición y haber aclarado lo que le faltaba por hacer a filósofos como Nietzsche en favor del nihilismo y en contra de la metafísica.

En razón de lo anterior, veíamos con incomodidad que no nos encontrábamos en posición de establecer qué podría haber agregado, en rigor, Nietzsche a la postura heterodoxa de Spinoza. A su vez, como complemento, necesitábamos saber qué imagen se había formado el autor del Zarathustra del filósofo holandés yendo más allá de su declarada afinidad, pathos común y cercanías doctrinarias, manifiestas en la recurrentemente citada carta a Overbeck (NIETZSCHE, 2010, p. 143). Es más, los ataques posteriores de Nietzsche a Spinoza había que ponerlos en contexto y, por tanto, era necesario revisar las fuentes formativas que le sirven de apoyo. Entendíamos, además, que Nietzsche cuando afirmaba el juicio juvenil de su semejanza con Spinoza, lo hacía sin haber realizado una lectura directa de sus textos (DE PABLOS, 2016, p. 140), pero, en modo alguno, bastaba con decir que su idea de la filosofía de Spinoza ha dependido por entero de Kuno Fischer. 
En resumen, no podíamos, por un lado, perfilar cuánto radicaliza Nietzsche a Spinoza sabiendo cuan conflictiva es la problemática de su supuesto ateísmo como ha quedado históricamente patente en la disputa Jacobi-Mendelssohn (FABRO, 1971, p. 29-33) - y, por otro lado, tampoco estábamos en condiciones de esbozar en justicia la imagen filosófica que Nietzsche se había formado del pensador holandés sin analizar los diversos interpretes que tuvo a la mano.

Por los motivos anteriores, la envergadura de nuestra pregunta inicial, nos demandaba replantearnos un objetivo más restringido que no significase adelantar pasos ineludibles para una evaluación futura más completa del radicalismo de uno y otro pensador. De esta manera, establecimos que nuestra indagación no estaría destinada a dar con una imagen general de Spinoza que dirimiera la disputa sobre su ateísmo, tampoco sería la idea general que Nietzsche se forjó de Spinoza, sino que buscaríamos esbozar el perfil filosófico del autor trazado por dos autores leídos por el filólogo, a saber: Heinrich Heine (CAMPIONI et al., 2003, p. 282) y Jean-Marie Guyau (CAMPIONI et al., 2003, p. 271). Serían, entonces, los juicios de ambos sobre el autor de la Ética los que nos permitirán calibrar si Nietzsche resulta ser más demoledor en los dominios del pensamiento ${ }^{1}$.

Debemos prevenir al lector que, en este lugar, no resolveremos, si acaso ambos autores, Heine y Guyau, dan una interpretación adecuada de Spinoza, pero sí iremos definiendo, o más bien ensayando, en forma general y en un radio investigativo más limitado, si conforme a dichas interpretaciones Nietzsche sería o no más radical que el filósofo holandés en algunos puntos específicos.

\section{Heine y Guyau dentro del contexto de las fuentes nietzscheanas sobre Spinoza}

Damos la razón a quien sostenga que cualquier evaluación que se haga del alcance que tuvo el pensamiento de Spinoza sobre Nietzsche, debe entrar a determinar, previamente, no sólo cuáles fueron sus propias intuiciones

\footnotetext{
${ }^{1}$ Tenemos presente que la interpretación de Spinoza concebida por Guyau se ha estudiado documentadamente (COMTE-SPONVILLE, 2007), pero bastante poco en directa relación con la recepción que Nietzsche hace de dicha interpretación.
} 
respecto al filósofo heterodoxo, sino, a su vez, el origen bibliográfico de sus juicios $\mathrm{o}$, al menos, determinar las particularidades de las interpretaciones que sus autores fuente defendieron.

Obedeciendo a lo anterior, podemos señalar que los especialistas en diversos ensayos y artículos, ya han dirimido bastante el problema de las lecturas de Nietzsche -a veces tras un duro trabajo hermenéutico y en otras ocasiones simplemente revisando las citas que hizo-, al punto que está bastante difundido que la fuente principal que le sirve al filósofo de Röcken para configurar su interpretación de Spinoza, es Kuno Fischer. A partir de ello, se ha llegado a la conclusión que Nietzsche utilizó fuentes secundarías y que ni las citas precisas de las obras, ni tampoco aquellas referencias en latín, son indicativas del manejo de los textos mismos de Spinoza (DE PABLOS, 2012, p. 535). Los investigadores han ido sumando influencias, siempre indirectas, para encontrar las raíces genéticas de la interpretación que Nietzsche hace del filósofo holandés (DE PABLOS, 2012, p.51). Así, por ejemplo, Mauricio Scandella ha destacado la influencia de Roux, Teichmüller y Bourget (SCANDELLA, 2012).

Ciertamente, los autores preocupados del asunto, son precisos y prodigan citas que dan cuenta de la relación de los juicios nietzscheanos con la visión presentada en dichas fuentes. Mas, a pesar de no olvidar destacar las influencias remotas en su comprensión de Spinoza, consideramos que se ha resaltado poco que uno de los primeros encuentros con el autor de la Ética es través de la prosa de Heinrich Heine. El poeta judío es una autoridad para Nietzsche por su estilo y porque, a su entender, nadie como él ha sabido decir la verdad, aquella que hiede, sin dejar de reír. En lo que respecta a la interpretación que el escritor de Düsseldorf hace de Spinoza, advertimos que destaca, entre todo, que el "panteísmo" del holandés incorporaría la idea de que Dios continúa manifestándose en el mundo y en la materia (HEINE, 1861, p. 138).

Debemos añadir que, tampoco, se puede dejar de lado la tardía, aunque importante, influencia de Jean-Marie Guyau en su interpretación de la moral como en la comprensión de la cosmología spinociana. Tenemos en cuenta que Raúl de Pablos, siguiendo a Wurzer (1974), le cita como una de las fuentes importantes (DE PABLOS, 2012, p. 52), pero no por ello se ha aquilatado aún suficientemente su 
repercusión en los juicios de Nietzsche. Es decir, junto con permanecer indeterminado hasta dónde llega la influencia del libro de Guyau La irreligión del porvenir (1886), leído y anotado por el autor del Zarathustra, tampoco se ha determinado si esta lectura le llevó a Nietzsche a consultar el análisis que el filósofo francés hace de Spinoza en sus obras La moral de Epicuro (1878) o La moral inglesa contemporánea (1879).

\section{Alcance del panteísmo spinociano en Heine y Guyau}

Cuando Heine afirmaba que hay algo que "no se dice pero que todos lo saben: el panteísmo es el secreto a voces en Alemania" (HEINE, 1861, p.140), estaba diciendo que el spinocismo era el secreto mejor guardado respecto de la visión y valorización del mundo. El poeta oponía este panteísmo — que empezaba secretamente a imperar como el horizonte futuro del pensar-, al deísmo y al espiritualismo y, al hacer esto, reprochaba a estos últimos el ser no más que modos juveniles e inmaduros de entender la realidad que santifica el espíritu y desdeña la materia toda vez que defiende la existencia de un "Dios exterior al mundo o sobre el mundo (über der Welt)" (HEINE, 1861, p. 131).

Sin embargo, como bien entiende Heine, acontece que espíritu y materia, pensamiento y extensión, lo ideal y lo real, espíritu y naturaleza, desde que ha habido un Spinoza, debe entenderse dentro de su "eterno paralelismo" (ewigen Parallelismus) y no en oposición (HEINE, 1861, p. 130). Tal identidad no solo permite volver absurdo el problema moderno del influxus physicus o comunicación de las sustancias, sino, también, entender el mundo como realización de lo divino y como unidad sustancial. Dice Heine:

Dios, al que Spinoza llama una sustancia y los filósofos alemanes Absoluto, "es todo lo que es" (ist alles was da ist), es materia tanto como espíritu; los dos son igualmente divinos, y aquel que insulte a la materia sagrada (die heilige Materie) es tan pecaminoso como el que peque contra el Espíritu Santo (HEINE, 1861, p. 131). 
Para el autor de Los dioses en el destierro, tal conciliación permite valorar el mundo material, sin ser materialista, y valorar el mundo del espíritu siempre y cuando implique la divinización de la materia.

Ahora bien, Heine estima que

solamente la estupidez y la maldad pudieron calificar tal doctrina de atea. Nadie se ha expresado sobre la divinidad de manera más sublime que Spinoza. En lugar de decir que negaba a Dios, pudiera decirse que negaba al hombre (HEINE, 1861, p. 128).

La opinión de Heine encuentra asidero en la siguiente declaración del propio Spinoza hecha en la carta XXX a Oldenburg y debería despejar toda duda: "La opinión que el vulgo tiene de mí, ya que no cesa de acusarme de ateísmo: también estoy obligado a rebatirla en todo los posible" (SPINOZA, 2007, p. 140). En consecuencia, si damos crédito a Heine, y confiamos en la aseveración del filósofo holandés, Nietzsche con sus juicios tomaría una perspectiva más extrema en lo referente a la negación de Dios.

Dirimiendo, de modo provisorio, la querella del ateísmo de Spinoza desde los juicios de Heine, no es peregrino sostener que era ateo, si ser teísta significa afirmar que Dios posee pensamiento y voluntad libre. Así lo han calificado muchos, entre ellos Jacobi —a quien burlescamente Heine motejara de "polémico hipócrita, oculto bajo el manto de la filosofía” (HEINE, 1861, p. 141)—, para él el ateísmo de Spinoza hay que sincerarlo y no ocultar en fórmulas su propuesta en la que el cosmos no es otra cosa que un ciego mecanismo (LESSING, 1982, p. 364). Como complemento explicativo, podemos recordar aquí algunos juicios de Schopenhauer y Feuerbach sobre Spinoza.

Considera el autor de Parerga que los prejuicios derivados del judaísmo llevaron a Spinoza a afirmar que "«el mundo mismo es Dios»", cuando si hubiese confiado sin más en la naturaleza, pudo haber dicho: "«no es cierto que Dios haya creado este mundo, sino que existe por propia perfección de potencia»" (SCHOPENHAUER, 1997, p. 166). Feuerbach juzga de modo similar el filosofar de Spinoza, es decir, muestra que, a pesar de haber logrado establecer los presupuestos cosmológicos para ser un verdadero naturalista, se mantuvo en una medianía al crear una cosa "mística" (mystisches) y "anfibia" (amphibolisches) que terminaba dejando maltrecho tanto a Dios como a la naturaleza (FEURBACH, 1847, p. 392). Al 
entender de Feuerbach, hay que disolver la contradicción spinociana que implica su monismo de la sustancia, dado que conduce, por un lado, a anular tanto a Dios como al mundo y, por otro, al absurdo de intentar unir dos condiciones que no pueden convivir en el filósofo. En razón de esto último, Feuerbach interpela a Spinoza preguntándole: “¿Por qué sigues queriendo ser como naturalista un teísta y como teísta un naturalista al mismo tiempo? (Warum willst du als Naturalist noch Theist und als Theist zugleich Naturalist sein?)" (FEUERBACH, 1847, p. 392).

No obstante, lo cierto es que, más allá de lo diga el filósofo de Danzig o Feuerbach, Spinoza sí parece confiar en la naturaleza y, por eso, es fundada la sospecha de que fueron ciertas medidas estratégicas las que impidieron que Spinoza se quedase con el mundo y su sola potencia. Las suspicacias sobre cuál es el verdadero extremo del filosofar de Spinoza aumentan, cuando él mismo revela que es recomendable acomodarse a la jerga de la gente y de la época para llegar a los objetivos previstos. Por tanto, Spinoza estaría ocultando lo más radical de su doctrina (MORALES, 1978, p. 46).

Ahora bien, si alguien sostiene que a la conclusión anterior se llega por una mala lectura de la recomendación que hace el filósofo, se puede echar mano del testimonio de Louis Meyer (1629-1681) quien, tal vez con una intención chismosa, sostiene que la palabra "Dios" en la Ética no aparecía en el original y que sólo por el llamado a la prudencia del traductor latino, la termina incluyendo, esto con el fin de matizar la atrevida exclusividad del uso del término "naturaleza" (MORALES, 1978, p. 45).

Ahora bien, Nietzsche, por su parte, encontrará expresado algo semejante en La irreligión del porvenir de Guyau, pues, este autor, sin considerar él mismo que Spinoza haya negado la existencia de Dios, le parece natural que desde ciertos enfoques teológicos su propuesta sea definida como atea y mecanicista. Dice Guyau:

Lo que la filosofía moral y religiosa ha objetado y objetará siempre al panteísmo de Spinoza, considerado como un posible sustituto de la religión, es su fanatismo optimista, en que todo se hace por la necesidad mecánica y brutal de las causas eficientes, sin especie alguna de finalidad interna, sin progreso verdadero (GUYAU, 1887, p. 399-400).

Por tanto, Nietzsche corroboraba a partir de esta lectura, que cabe que a Spinoza se le pueda interpretar dando el paso a la explicación del mundo desde su 
propia potencia y, al dar lugar a esta explicación inmanente y física del mundo, la radicalización nietzscheana consistiría solo en develar como ficticia las relaciones causales y redefinir el resorte que impulsa el devenir.

Insistimos que, para Guyau, pese a que muchos extremen las consecuencias del pensar spinociano, dar el paso a la despersonalización de Dios para identificarlo con el mundo, no supone, desterrar ipso facto lo divino, pues este paso, para él, solo podría darlo, como veremos más adelante, una mirada "científica” (GUYAU, 1887, p. 400), es decir, la del naturalista cabal.

En consecuencia, según lo anterior, Nietzsche sabe por la lectura de Heine y Guyau de todo lo radical que puede ser interpretado el pensamiento de Spinoza, pero, parece querer dejarlo dentro de ciertos límites que permitan que su propia propuesta sobresalga por su extremismo o, al menos, no atribuye esa intención al autor sino que la concibe como una consecuencia derivada de su pensar.

\section{Algunas de las posibles radicalizaciones hechas por Nietzsche: su lectura desde Guyau}

La extrapolación del pensamiento de Spinoza a la doctrina de la evolución, puede ser entendida como un paso más radical en el modo de entender el mundo. Pues, pese a que las corrientes evolucionistas suelen poner nuevos fines donde los habían quitado, sus ideas, bien llevadas, alcanzan para entender la vida desde la más completa inmanencia. Guyau piensa que si bien el pensar de Spinoza se puede entender como la base ideal para plantear la mirada de la ciencia —entiéndase el materialismo y sus derivaciones-, es solo esta última la que puede ver la realidad en toda su extramoralidad (GUYAU, 1887, p. 400).

Se puede agregar que la crítica nietzscheana a Spinoza, también se realiza dentro de la discusión en torno al evolucionismo. Veremos que, dentro de estos lindes, Nietzsche llevará a cabo una de sus críticas al filósofo holandés más conocidas que, desde cierto ángulo, podría considerarse como una de la más acomodaticias (NIETZSCHE, 2001, p. 343). 


\section{Contra la unidad spinociana y radicalización del sentido extramoral del mundo}

El filósofo judío piensa que ha demostrado que "la naturaleza no tiene fin alguno prescrito a ella y que todas las causas finales sólo son ficciones de los hombres" (SPINOZA, 1980, p. 78). Mas, como advierte Guyau, "la exclusión de toda finalidad inmanente a las cosas no es pues indispensable al panteísmo", dado que, según él, "se puede hasta concebir un panteísmo, en algún modo moral, que admitiera el sentido moral del mundo" (GUYAU, 1887, p.400). Esto parece tan cierto que incluso el propio Spinoza, según lo entiende esta vez Nietzsche, se muestra anclado a la finalidad y, a la par, a la moral, justamente, al dar sentido a la vida en el goce del conocimiento de lo permanente. En cierto modo, Nietzsche no presta oídos al juicio de su apreciado Mainländer sobre el antiteleologismo del pensador holandés, puesto que no atiende a que el autor de la Filosofía de la redención le inscribe en el "panteísmo auténtico", es decir, en aquel que se sitúa más allá de la finalidad en la medida en que el mundo está dado desde la eternidad. Para Mainländer, aparece el "panteísmo evolutivo", como contraparte del defendido por Spinoza, que le parece "afeminado" y que, por plagado de metas parciales, se muestra "inconsolable" (MAINLÄNDER, 2014, p.419).

Sucede, además, en Spinoza, de acuerdo con la interpretación de Guyau, que

gracias a la presencia de Dios en todas partes, el mundo viene a convertirse en un verdadero ser viviente que tiene su unidad orgánica, su ley de evolución determinada de antemano como la del embrión. Lo que caracteriza al panteísmo, desde este punto de vista, es, pues, continúa Guyau - la importancia que concede a la idea de unidad substancial del mundo (GUYAU, 1887, p. 398).

Para Guyau, es cierto que la ciencia en su faceta evolucionista, podría carecer de la "autenticidad" propia del panteísmo de Spinoza, pero sí le parece claro que posee la "honestidad" necesaria para defender que

el mundo es probablemente una fuerza única, materialmente hablando, pero en un estado de dispersión moral y psíquica. Todo lo que es organizado, viviente, sentiente y pensante, es finito para nuestro conocimiento, y la equivalencia de las fuerzas del universo en que se apoya la ciencia, no tiene nada en común con la centralización de las fuerzas. Acaso es, precisamente, porque no tiene dirección de conjunto, por lo que luchan una contra otra y se mantienen la una y la otra. [...] La unidad del mundo, lo diremos una vez más, no está hecha; 
no se realiza probablemente más que en nuestro espíritu: es solamente por nuestro espíritu como puede pasar a las cosas y a los seres (GUYAU, 1887, p. 401).

Por tanto, solo por una ficción, el bien supremo podría ser el conocimiento de la unidad de nuestro espíritu en el universo. Desde estas consideraciones, se entiende que los monistas del siglo XIX digan expresamente apartarse de Spinoza cuando se ven necesitados de negar, como correlatos de la unidad del mundo, la identidad de la physis y la psiquis (HAECKEL, 1892, p. 10).

Al mismo tiempo, si nos fijamos en su interpretación de la moralidad del mundo, podemos decir que pese a que Spinoza no defendería, entonces, la concepción de un mundo orientado al caos y a la dispersión, es manifiesto que sí se sitúa más allá del bien y del mal y entiende, como sostiene Guyau, que "la moral es la que es relativa, y la que es absoluta es la naturaleza” (GUYAU, 1886, p. 228). Esto se debe a que "el bien y el mal no señalan nada positivo" (GUYAU, 1886, p. 228), son simples relaciones que surgen desde una mirada antropocéntrica, que ve dichas relaciones como propiedades de las cosas. Dice Spinoza: "[...] haré ver cómo han salido de él —del hombre- los prejuicios relativos al bien y al mal, al mérito y al pecado, a la alabanza y a la censura, al orden y a la confusión, a la belleza y a la fealdad y a otros objetos de igual especie" (SPINOZA, 1980, p. 76).

Obviamente una inversión moral de esta especie representa, modernamente, un hito difícil de superar, por lo que no sería descabellado hacerse una imagen de Nietzsche como un filósofo que no hace más que empujar, como expresamos más arriba, lo que ya va cayendo.

Spinoza, de alguna manera, ya había pensado la vida sin los aditamentos humanos y, consecuentemente, la había entendido careciendo de un significado moral ínsito. Pese a ello, habiendo dado el paso decisivo, faltaba, según parece, la consumación de la tendencia extramoral hasta llegar a superar la supuesta unidad moral del mundo y la posible redención del mal a partir de una mirada de conjunto. Por tanto, el autor de la Ética, estaría más acá de Nietzsche, pues entendería que hay un summun bonum que - cuando vamos encaminándonos a él hay una intelección del obstáculo que impide su goce-, se identifica con aquello que genera la felicidad más perenne. Para Spinoza, se trata de concebir que "Dios es eterno", es decir, de acceder al "amor intelectual" que proviene del "tercer género de conocimiento" bajo 
la "especie de la eternidad" (SPINOZA, 1980, p. 387). Se añade un elemento que hacía notar Fouillée: hay un inmoralismo, no un amoralismo, en su panteísmo al tener que identificar a Dios con ciertas imperfecciones y males del mundo (FOUILLÉE, 1872).

No cabe duda que Nietzsche no podría aceptar con Spinoza ese optimismo que, sintonizando con la inmutabilidad de Dios, defiende que todo lo que es bueno es lo mejor posible. Todo indica que es Nietzsche quien llega a ver la realidad del modo más anticristiano y antiteleológico posible al quitarle la unidad de sentido, es decir, consumando el nihilismo. Por ello, "«la deshumanización de la naturaleza»" que es el trabajo que el mismo Nietzsche reconoce como obra de Spinoza no significa ese radical "chaos sive natura" (NIETZSCHE, 1999b, p. 519). Sólo en Nietzsche el inmanentismo metafísico se convierte en inmanentismo interpretativo.

Ahora bien, es el mismo Schopenhauer, el mismo que ve la voluntad en la naturaleza prodigándose por doquier, quien no quiso asumir una de las consecuencias de su propia perspectiva "biocéntrica", como es la de entender al mundo teniendo un significado exclusivamente físico. Una conclusión de esta naturaleza respecto del carácter del mundo es, a su juicio, "la auténtica perversidad de la intención (die eigentliche Perversität der Gesinnung)" (SCHOPENHAUER, 1874, p. 215). En el fondo, para él, un biocentrismo que sitúa el devenir de la vida "más allá del bien y del mal" es "aquello que la fe ha personificado como el Anticristo (was der Glaube als den Antichrist personifiziert hat)" (SCHOPENHAUER, 1874, p. 215). Pero, es justamente su discípulo póstumo, Nietzsche, el que afirma esta "perversidad" y realiza el Anticristo al negar el valor moral del mundo a través de las conceptualizaciones propias de su filosofar, como son la "muerte de Dios" y la "inocencia del devenir". Podría afirmarse que Nietzsche, como Spinoza, tiene su propio "tercer grado de conocimiento", que ya no se lleva a cabo sub specie aeternitatis, sino a partir de una lectura del mundo sub specie interpretationis, es decir, desde el "nuevo infinito" que se suscita al verlo "bajo sus formas perspectivistas" (NIETZSCHE, 2001, p. 392). En este enfoque, que se resume en el $\int 374$ de la Ciencia jovial, exalta la radicalidad de su perspectivismo y, creemos, se enfrenta, sin mencionarlo, al carácter autorreferencial y de ángulo estrecho que advierte en el 
criticismo kantiano y, de manera global, a los presupuestos cosmológicos spinocianos por los que alguna vez se sintió seducido.

\section{De la autoconservación spinociana al acrecentamiento del poder}

Como dijimos más arriba, una de las corrientes que se siente deudora de Spinoza, pese a una evidente toma de distancia, es el evolucionismo (GUYAU, 1887, p. 400). De hecho, una de las críticas más difundidas de entre las que hace Nietzsche al filósofo holandés, se sitúa en el mismo marco de sus objeciones al evolucionismo.

De forma similar al modo en que reprocha la insuficiencia de la "voluntad de vivir" schopenhaueriana, Nietzsche criticará la "lucha por la vida" de Darwin equiparándola al conatus sese conservandi de Spinoza (SPINOZA, 1980, p.281). Nietzsche supone que la idea de "«voluntad de vida» no ha conquistado a los ojos de la ciencia el derecho de ciudadanía” (NIETZSCHE, 1999a, p. 406), y, en concordancia con ello, afirmará que el instinto de conservación, que igualmente involucra la lucha por la vida y la autoconservación spinociana, son principios superfluos para entender el fondo de la existencia. La autoconservación es una consecuencia indirecta derivada de la voluntad de poder. Es sabido que son múltiples los fragmentos en que Nietzsche ataca el darvinismo y toda la corriente de pensamiento que no ponga al crecimiento y la expansión de la vida como centro del movimiento del mundo.

Sin embargo, pese a lo afirmado por Nietzsche, Guyau explica que el bien relativo de Spinoza, como es la satisfacción del deseo que se complementa con "la tendencia del ser a persistir en el ser", es un poder conseguir conservarse, por lo que es difícil, si seguimos a Guyau, no deducir de ahí ciertos rasgos de la voluntad de poder (GUYAU, 1886, p. 228). En consecuencia, Guyau y, como se verá, Fouillée terminan afirmando que el momento del aumento en el conatus sese conservandi se deriva del filosofar de Spinoza, pero no es un elemento que discierna y defienda el propio filósofo. Guyau cree encontrar recién en Spencer elementos suficientes para 
que el principio de persistencia en el ser pueda derivar, claramente, en "progreso", es decir, con los presupuestos del filósofo inglés se puede afirmar que "toda conservación es evolución” (toute conservation est une évolution) (GUYAU, 1879, p. 195). Por ello, Guyau puede calificar a Spencer como "un Spinoza positivista” (GUYAU, 1879 , p. 258) que concilia necesidad natural y ausencia del libre arbitrio con la evolución. Por tanto, vemos que Guyau hace hincapié, como Nietzsche, que el rasgo fundamental del fenómeno vida no es explicado por el autor de la Ética aunque sí está contenido, de alguna manera, en su sistema. Nietzsche afirma:

\begin{abstract}
El principio de Spinoza de la autoconservación tendría propiamente que ponerle término a la alteración: pero el principio es falso, lo contrario es verdadero. Justamente en todo lo viviente es sumamente claro mostrar que lo hace todo para no conservarse, sino para llegar a ser más (NIETZSCHE, 1999d, p. 301).
\end{abstract}

Mas, el celo de Nietzsche por no querer ver el momento del aumento en el conatus spinociano, que parece ocultarlo como si quisiera dejarlo sin crédito en la configuración de su propia doctrina, en ocasiones cede, pues llega a afirmar, citando e interpretando claramente a Spinoza, que "«lo que hacemos lo hacemos para conservar y acrecentar nuestro poder»" (NIETZSCHE, 1999c, p. 206). Pese a esta concesión a favor de un spinocismo explícitamente afín a la voluntad de poder, Nietzsche prefiere destacar dos ideas que cierran toda posibilidad de expansión y acrecentamiento en Spinoza, ideas que eran recalcadas, también, por Guyau: "la inmutabilidad de la sustancia perseverando en el ser" y la concepción de que "lo perfecto es lo real" y que, por tanto, el mundo no puede dar lugar a un ideal que lo rebase (GUYAU, 1879, p. 404).

Ahondando en lo sostenido, queda de manifiesto que la idea, que suele pasar como un hallazgo netamente nietzscheano, que afirma que un poder no es poder sin serle inherente el aumento, era ya central en la concepción de mundo trazada por Fouillée y seguida, a su modo, por su discípulo y yerno Guyau. Esta consideración crítica que toca, con diversos grados de pertinencia, tanto a Spinoza, a Schopenhauer como al darvinismo, había sido hecha pública, precisamente, en 1872 en el libro de Fouillée Libertad y determinismo. El autor francés había escrito lo siguiente anticipando la idea de voluntad de poder de Nietzsche: 
Muchos filósofos, sobre todo los deterministas, han hecho consistir la esencia de toda fuerza activa en la conservación de sí mismo o en la permanencia. El ser, dice Spinoza, tiende a perseverar en el ser y mantenerse tal y cual es [...] Mas, en primer lugar, decir que el ser tiende a ser lo que es, es contradecirse; porque no es posible tender a ser lo que ya se es; la tendencia indica alguna cosa nueva a obtener, e implica una noción de diferencia. Del mismo modo, la perseverancia en el ser implica algo distinto al reposo y la inercia, y no es en manera alguna una fórmula de pura identidad, porque la pretendida conservación de sí mismo es también un acrecentamiento (FOUILLÉE, 1872, p. 128-29).

Según lo anterior, no sólo se juzga la necesidad de entender la realidad en términos de acrecentamiento, sino que se nos ilustra respecto a un modo de entender el conatus sese conservandi de Spinoza, es decir, suponiéndolo insuficiente para explicar el devenir de la vida, pero, mostrándolo conteniendo virtualmente el momento expansivo.

De acuerdo con esto último, Nietzsche extremaría la filosofía del holandés, pero de una forma que está lejos de ser exclusiva, pues, hay que reconocer que al incorporar el momento del crecer en la voluntad (MARTÍNEZ, 2007, p. 43-44), podría estar complementando el pensar spinociano, pero no agregando mucho a lo que filósofos como Fouillée establecieron antes que él y que vieron implícito en su conatus. Por ello, no debe extrañar que luego de conocer la obra de Nietzsche y los denuestos a Guyau deslizados entre loas, el autor de Libertad y determinismo dedicara parte de sus esfuerzos a demostrar cuánto les había copiado el autor alemán a él y al propio Guyau (MARTÍNEZ; JEANNET; MEDEL, 2008).

\section{Conclusión}

El radicalismo de Nietzsche siempre podrá considerarse evidente, mientras que el de Spinoza estará siempre bajo un signo de interrogación respecto de su alcance. Es manifiesto que el panteísmo, el fatalismo, la teleología, etc., del autor de la Ética dan lugar a querellas no muy distintas a las suscitadas a instancias de su posible ateísmo.

Ese panorama interpretativo afecta también a la evaluación que el propio Nietzsche hace de Spinoza. Sin embargo, el autor del Zarathustra pese a considerarlo como un filósofo que no deja ver con claridad su fondo último y que se siente necesitado de "disimular" (Jacobi), entiende que aquello que permanece oculto sigue 
estando atrapado en la metafísica y la teleología. Es más, al entender de Nietzsche, en Spinoza sucede que mientras su razón se percata de la inocencia del devenir, sus afectos, en la medida que son "devorados por un siniestro ardor vengativo", "tienen un odio judío al dios judío" (NIETZSCHE, 1998, p.130). Por tanto, el "Uno en Todo" no es la visión soberana superadora de toda reactividad, sino la resistencia al Dios personal.

De acuerdo con nuestro análisis, Heine muestra a Spinoza como un sublime teólogo que consuma la adecuada mirada de lo divino y contribuye de forma definitiva a su necesaria desantropomorfización. Esta forma de concebir el pensamiento de Spinoza, corre a favor de valorar a Nietzsche, y a que el mismo se evalúe, defendiendo un enfoque cosmológico de mayor radicalismo y singularidad.

Por su parte, Guyau destaca principalmente los alcances tácitos de la doctrina spinociana, al considerarla como un anticipo teológico y metafísico de lo que será la visión extramoral de la ciencia. Con ello, Guyau da razones suficientes a Nietzsche para considerarse él, y no Spinoza, como el reivindicador más radical de un devenir inocente y "más allá del bien y del mal", es decir, para entronarse como el verdadero naturalista. A su vez, al entender del filósofo francés, la idea de "evolución” será el elemento faltante del sistema spinociano que, a su juicio, será añadido por Spencer. Sin duda, esta atribución debe haber suscitado el completo rechazo de Nietzsche, es decir, debe haber sido chocante advertir que Guyau calificaba de avance el "progreso" utilitarista defendido por Spencer. Nietzsche, contrariamente a Guyau, pensaba que el filósofo inglés con su idea de progreso, por un lado, se contentaba con sustituir el ideal por una mediocridad que se solaza en la comodidad (comfort) y, por otro, reemplazaba el refinamiento de la guerra y el conflicto por el triunfo del altruismo.

Guyau, coincidiría con Schopenhauer y Feuerbach, en que Spinoza ha propuesto en su sistema una concepción de la sustancia que, en su intento monístico y totalizante de ver el mundo, seguía en una medianía necesitada de radicalización. Es decir, esta medianía entre Dios y el mundo es, para Schopenhauer, un "absurdo" y, para Feuerbach, una concepción “anfibia” y, para los dos filósofos, no más que una anulación tanto de Dios como del mundo. Spinoza, pondera Feuerbach, se mantiene todavía anclado al conflicto medieval que se da entre "fe y razón" y 
aunque opta por poner a la teología al servicio de la filosofía, a diferencia de la "filosofía diplomática" (Philosophie diplomatischer) de Leibniz, concibe la personalidad del hombre como un modo de la divinidad (FEUERBACH, 1908, p. 9-10). Sin embargo, Guyau a diferencia de ambos filósofos alemanes, no pide a Spinoza algo que será tarea, o consecuencia, posterior.

Nietzsche piensa que es él quien da el paso decisivo a la naturaleza, a la soledad de la inmanencia, es decir, se arroga el "mérito" de pensarla sin Dios y sin un significado moral más allá del cuño interpretativo del hombre y de los seres vivos en general. Ciertamente, Nietzsche estima, como Spinoza, que el juicio acerca del bien y del mal es una relación, pero, para el filósofo alemán esta evaluación moral guarda un vínculo con el fenómeno primordial de la naturaleza que nos obliga a entender el ser como crecer, en otras palabras, como actividad vital que quiere más de sí misma y no sólo su simple conservación.

Desde la interpretación de Heine, Spinoza funda y establece las bases de esa gran catedral que es el idealismo alemán -léase la "filosofía alemana"-, pero, de las opiniones del sarcástico intérprete, también se desliza que en esos mismos cimientos se encuentra la raíz de destrucción de ese gran edifico. La divinización de la materia que, desde el "ilimitado desinterés" de Dios, carece de finalidad, se desarrolla en la filosofía posterior en sendas extrapolaciones que derivarán en el más rotundo nihilismo y, sin duda, en la posterior afirmación del "sentido" pespectivístico de la existencia defendido por Nietzsche. Como Guyau, Nietzsche defenderá un monismo que, en su radicalismo, ya no es místico, ni está obsesionado con establecer paralelismos o síntesis entre materia y espíritu, sino que entenderá que "el mundo es un sólo y mismo devenir" (le monde es un seul et même devenir) (GUYAU, 1887, p. 437).

Finalmente, insistimos en que para visualizar con mayor nitidez el contraste que personalmente Nietzsche desarrolla frente al filosofar de Spinoza, es necesario seguir destacando filiaciones doctrinarias y lecturas que realizó, incluso aquellas que, siendo analizadas con menor recurrencia, pueden aportar elementos interpretativos novedosos. 


\section{Referencias}

CAMPIONI, G. et al. Nietæsches persönliche Bibliothek. Berlin-New York: Walter de Gruyter, 2003.

COMTE-SPONVILLE, A. Jean-Marie Guyau et Spinoza. In: TOSEL, A.; MOREAU, P.F.; SALEM, J. (dir.). Spinoza au XIXe siècle. Actes des journées d'études organisées à la Sorbonne, 9 et 16 mars, 23 et 30 novembre 1997. Paris: Publications de la Sorbonne, 2007. p. 281-294.

DE PABLOS, R. La filosofía vivida: pensamiento y transformación en Spinoza y Nietzsche. Madrid: Servicios de Publicación. Universidad Complutense de Madrid, 2012.

DE PABLOS, R. La voluntad como deseo consciente: Kuno Fischer entre Spinoza y Nietzsche. Anales del Seminario de Historia de la Filosofía, v. 33, n. 1, p. 137-161, 2016.

FABRO, C. Génesis histórica del ateísmo contemporáneo. In: El ateísmo contemporáneo, v. II, Madrid: Cristiandad, 1971. p. 19-66.

FEUERBACH, L. Geschichte der neuern Philosophie von Bacon von Verulam bis Benedict Spinoza. In: Sämtliche Werke, v.4. Leipzig: Otto Wigand, 1847.

FEUERBACH, L. Vorlesungen über das Wesen der Religion. Nebst Zusätzen und Anmerkungen. Stuttgart: Frommanns, 1908.

FOUILLÉE, A. La liberté et le déterminisme. Paris: Librairie philosophique de Ladrange, 1872.

GUYAU, J.-M. La Morale anglaise contemporaine, morale de l'utilité et de l'évolution. Paris: Germer Baillière, 1879.

GUYAU, J.-M. La morale d'Epicure et ses rapports avec les doctrines contemporaines. Paris: Felix Alcan, 1886.

GUYAU, J.-M. L'irreligion de l'avenir, étude de sociologie. Paris: Felix Alcan, 1887.

HAECKEL, E. Der Monismus als Band zuischen Religion und Wissenschaft. Bonn: Emil Strauss, 1892.

HEINE, H. Über Deutschland. In: Sämtliche Werke: rechtmäßige Original-Ausgabe, v. 5. Hamburg: Hoffmann und Campe, 1861.

LESSING, G.-E. Escritos filosóficos y teológicos. Madrid: Editora Nacional, 1982.

MAINLÄNDER, P. Filosofía de la redención. Madrid: Ediciones Xorki, 2014.

MARTÍNEZ, P. Nieţssche y el despliegue de la libertad. Santiago de Chile: RIL, 2007.

MARTÍNEZ, P.; JEANNET, A.; MEDEL, C. Nietzsche y la polémica con Fouillée. Intus-Legere, v. 2, n.1, p. 79-91, 2008.

MORALES, C. Baruch Spinoza: Tratado teológico-político. Madrid: Magisterio Español, 1978.

NIETZSCHE, F. Correspondencia. IV. Enero 1880 - Diciembre 1884. Trad. M. Parmeggiani. Madrid: Trotta, 2010. 
NIETZSCHE, F. Kritische Studienausgabe. v. 8. München: Walter de Gruyter, 1999a.

NIETZSCHE, F. Kritische Studienausgabe. v. 9. München: Walter de Gruyter, 1999b.

NIETZSCHE, F. Kritische Studienausgabe. v. 12. München: Walter de Gruyter, 1999c.

NIETZSCHE, F. Kritische Studienausgabe. v. 13. München: Walter de Gruyter, 1999d.

NIETZSCHE, F. La ciencia jovial. Madrid: Biblioteca Nueva, 2001.

NIETZSCHE, F. Poesía completa. Madrid: Trotta, 1998.

SCANDELLA, M. Did Nietzsche Read Spinoza? Some Preliminary Notes on the Nietzsche-Spinoza Problem, Kuno Fischer and Other Sources. Nietzsche-Studien, v. 41, p. 308-332, 2012.

SCHOPENHAUER, A. Parerga und Paralipomena In: Sämtliche Werke, v. VI. Leipzig: Brockhaus, 1874.

SCHOPENHAUER, A. Parerga y Paralipomena. Escritos filosóficos menores, v. I. Trad. Edmundo González Blanco. Málaga: Ágora, 1997.

SPINOZA, B. Epistolario, Trad. Oscar Cohan, Diego Tatián, Javier Blanco. Buenos Aires. Colihue, 2007.

SPINOZA, B. Ética, Trad. Ángel Rodríguez Bachiller. Buenos Aires: Aguilar, 1980.

WURZER, W. Nietæssche und Spinoza. Freiburg: Albert Ludwigs-Universität, 1974.

RECIBIDO: $28 / 11 / 2019$

APROBADO: $12 / 02 / 2020$

RECEIVED: $11 / 28 / 2019$

APPROVED: 02/12/2020 